\title{
Lactate Biosensing for Reliable On-Body Sweat Analysis
}

\author{
Xing Xuan, Clara Perez-Rafols, Chen Chen, Maria Cuartero and Gaston A. Crespo* \\ Department of Chemistry, School of Engineering Sciences in Chemistry, Biotechnology and Health, \\ KTH Royal Institute of Technology, Teknikringen 30, SE-100 44, Stockholm, Sweden
}

*Corresponding author: gacp@kth.se.

\section{Table of Contents}

\section{EXPERIMENTAL SECTION}

Reagents, materials and instrumentation..... SI-3

Sensor fabrication $\mathrm{SI}-3$

On-body and off-body tests. SI-4

Tables SI-6

Table S1. Compositions of the outer membranes used in lactate biosensors SI-6

Table S2. Lactate concentration obtained during on-body tests using the epidermal patch and IC measurements.

Figures SI-8

Figure S1. Schematic draw of $\mathrm{pH}, \mathrm{T}$, and lactate sensors layer...... SI-8

Figure S2. Schematic draw of one channel cell SI-8

Figure S3. Characterization of the lactate biosensor in batch mode SI-9

Figure S4. Time trace of the chronoamperometric response SI-9

Figure S5. Resiliency test. SI-10

Figure S6. Calibration curve for the $\mathrm{pH}$ and $\mathrm{T}$ sensors SI-10

Figure S7. Influence of the flow rate and reversibility studies SI-10

Figure S8. (a) Potentiometric response of Carbon/CNTs/ETH500 membrane SI-11

Figure S9. Off-body validation 


\section{EXPERIMENTAL SECTION}

Reagents, materials and instrumentation. Potassium hexacyanoferrate(III) (CAS-13746-66-2, >98\% purity), iron (III) chloride (CAS-7705-08-0, >97\% purity), sodium L-lactate (CAS-867-56-1), chitosan (CAS-9012-76-4), Nafion perfluorinated resin solution 5\% (CAS-31175-20-9), bis(2-ethylhexyl)sebacate (DOS) (CAS-122-62-3, $\leq 97 \%$ purity), polyurethane Tecoflex SG80A (PU) (CAS- 68400-67-9), high molecular weight poly(vinyl chloride) (PVC), tetradodecylammonium tetrakis(4-chlorophenyl)borate (ETH 500), and tetrahydrofuran (THF) (CAS-109-99-9) were purchased from Sigma-Aldrich. Analytical grade chloride salts of ammonium (CAS-12125-02-9), magnesium (CAS-7786-30-3), potassium (CAS7447-40-7), sodium (CAS-7647-14-5), as well as sodium carbonate (CAS-497-19-8) and sodium phosphate (CAS-7558-79-4) were purchased from Sigma-Aldrich. Lactate oxidase (LOx) was purchased from Sorachim SA, Switzerland (LAX-18C). Silver/silver chloride $(\mathrm{Ag} / \mathrm{AgCl})$ ink and carbon ink were purchased from Henkel, German. The substrate material polyester sheet was purchased from RS components, Sweden. PU filament for the 3D printing of the sampling cell, TPU 95A, Ultimaker Material 1756 was purchased from Ultimaker B.V., Netherlands. All solutions were prepared in $18.2 \mathrm{M} \Omega$ $\mathrm{cm}^{-1}$ doubly deionized water (Milli-Q water systems, Merck Millipore). Macroduct for iontophoresis method was purchased from ELITechGroup, Netherlands. Artificial sweat was prepared as background solution for all the experiments, which contains $60 \mathrm{mM} \mathrm{NaCl}, 6 \mathrm{mM} \mathrm{KCl}, 5 \mathrm{mM} \mathrm{NH}_{4} \mathrm{Cl}, 0.08 \mathrm{mM} \mathrm{MgCl}_{2}$, $2.6 \mathrm{mM} \mathrm{NaHCO}_{3}$ and $0.04 \mathrm{mM} \mathrm{Na}_{2} \mathrm{HPO}_{4}(\mathrm{pH} 8.5)^{1}$.

Amperometric measurements were performed with a potentiostat (Autolab, Metrohm Nordics $A B$, Sweden). For fundamental studies, a commercial single junction $\mathrm{Ag} / \mathrm{AgCl} / 3 \mathrm{M} \mathrm{KCl}$ reference electrode (Metrohm Nordic, Sweden) and a platinum counter electrode (Metrohm Nordic, Sweden) were employed. For on-body and off-body validation, lactate content in sweat samples was additionally measured by ion chromatography (IC) (850 Professional IC, Metrohm AB, Sweden). The masks for screen printed electrode and adhesive transfer tape were designed with Auto-Cad software and fabricated using Silhouette Cameo cutter (Silhouette Inc., USA). The microfluidic cell was designed with Auto-Cad and printed with Ultimaker 3 printer (Ultimaker B.V., Netherlands). In the flow mode experiments, the samples flow through plastic tube $(51 \mu \mathrm{m}$, SC0005T, ISMATEC, German) to the microfluidic cell by using peristaltic pump (ISMATEC IPC series, Cole-Parmer GmbH, Germany). Thickness measurements were carried out with a Dektak 150 Stylus surface profiler (Veeco, USA).

Sensor fabrication. For manual screen-printing of carbon and $\mathrm{Ag} / \mathrm{AgCl}$ electrodes flexible substrate material polyester sheets were first cleaned with ethanol and dried with nitrogen for further use. Subsequently, the conductive inks were screen-printed on the polyester substrate and dried in the oven at $100^{\circ} \mathrm{C}$ for 1 hour.

The modification to obtain the lactate working electrode consisted of a layer-by-layer deposition method. For the Prussian Blue (PB) layer, $3 \mu \mathrm{L}$ of $0.1 \mathrm{M}$ potassium ferricyanide and $3 \mu \mathrm{L} 0.1 \mathrm{M}$ iron (III) chloride were drop-casted on the carbon electrode, thoughtfully mixed, and left to react for $20 \mathrm{~min}$ at room temperature. Afterwards, the excess of $\mathrm{PB}$ was cleaned with $0.01 \mathrm{M} \mathrm{HCl}$ and the resulting layer was annealed in the oven at $100^{\circ} \mathrm{C}$ for 1 hour. The deposition of the enzyme layer was carried out by dropcasting $2.5 \mu \mathrm{L}$ of a solution containing $15 \mathrm{mg} / \mathrm{mL}$ LOx, $5 \mathrm{mg} / \mathrm{mL}$ BSA and $0.5 \%$ wt Nafion. This layer was 
allowed to dry for $20 \mathrm{~min}$ at room temperature prior to depositing the outer polymeric membrane. For this purpose, a volume of $1.5 \mu \mathrm{L}$ of a solution containing $3 \mathrm{mg} / \mathrm{mL}$ ETH $500,33 \mathrm{mg} / \mathrm{mL}$ PVC and 66 $\mathrm{mg} / \mathrm{mL}$ DOS in THF was drop-casted and dried at room temperature for $20 \mathrm{~min}$. Finally, the electrode was conditioned overnight at $4{ }^{\circ} \mathrm{C}$ in artificial sweat before further measurement. The same conditions were employed in the storing of the sensors.

A PANI-based $\mathrm{pH}$ sensor was used to detect $\mathrm{pH}$ in sweat. To deposit PANI on the carbon electrode, cycling voltammetry (from -0.2 to $0.8 \mathrm{~V}, 50 \mathrm{mV} / \mathrm{s}, 15$ scans) was carried out in a solution containing 0.1 $\mathrm{M}$ aniline in $0.5 \mathrm{M} \mathrm{H}_{2} \mathrm{SO}_{4}$ and $0.1 \mathrm{M} \mathrm{NaPF}_{6}{ }^{2}{ }^{2}$ For the reference electrode, a $\mathrm{Ag} / \mathrm{AgCl}$ screen-printed electrode was covered with a reference membrane containing $78 \mathrm{mg}$ polyvinyl butyral and $50 \mathrm{mg} \mathrm{NaCl}$ $\mathrm{mg}$ in $1 \mathrm{~mL}$ methanol, as previously reported. ${ }^{1}$ Electrodes were conditioned overnight in $3 \mathrm{M} \mathrm{KCl}$. For the T sensor, a layer of $0.5 \mu \mathrm{L}$ MWCNTs ( $1 \mathrm{mg} / \mathrm{mL}$ CNTs in THF) was drop casted between two carbon electrodes. Subsequently, the electrodes were dried in the oven for 1 hour at $100{ }^{\circ} \mathrm{C}$ to remove any water content. ${ }^{1}$

Each set of electrodes were connected to aluminum wires by using commercial 3-pin (lactate) or 2-pin ( $\mathrm{pH}$ and temperature) connectors (5-520315-3-ND and A124763-ND, respectively, Digi-Key).

On-body and off-body tests. Before each on-body test, the lactate biosensors were calibrated in flow mode using solutions of $5,10,15$, and $20 \mathrm{mM}$ lactate in artificial sweat. Afterwards, the patch was attached to the skin of the volunteer by means of adhesive tape, and further secured with straps. Four different body locations were considered for the sensor placement (i.e., forehead, back, thigh, and arm) to test the sensor performance under different conditions: active/passive muscle, low/high sweating rate.

In cycling on-body tests, sweat samples were collected for validation purposes following a previously reported protocol. ${ }^{3}$ Briefly, cotton pads are attached to the skin next to the sensor and sealed with Hydrofilm water-resistant tape to avoid evaporation and/or contamination. After a certain amount of time, the pad is removed and immediately squeezed using a syringe to extract the sweat. Sweat samples were stored in the fridge until further analysis.

Iontophoresis tests were performed using a commercially available medical grade device (Macroduct) according to the specified instructions. For each subject, iontophoresis was applied twice, one for onbody measurement with the epidermal patch and the other (in the other arm) for sweat collection. In the on-body measurements, the epidermal patch was attached to the same region right after the iontophoresis process. Sweat collection was performed with an elliptic collector for 15-40 min depending on the sweat rate of each specific subject.

In the off-body validation of the lactate biosensor, the collected sweat samples were analyzed in flow mode using the developed microfluidic cell but also with the IC (850 Professional IC, Metrhom, Switzerland) with conductivity detection and using a MetrosepA Supp 5 - 150/4.0 (ref. 6.1006.520) column, $1 \mathrm{mM} \mathrm{NaHCO} / 3.2 \mathrm{mM} \mathrm{Na}_{2} \mathrm{CO}_{3}$ buffer with a flow rate of $0.8 \mathrm{~mL} \mathrm{~min}^{-1}$ as mobile phase and $100 \mathrm{mM} \mathrm{H}_{2} \mathrm{SO}_{4}$ as suppressor.

The on-body evaluation of the wearable device developed in the present work was performed in compliance with European and Swedish legislations and fundamental ethical principles, including those 
reflected in the Chapter of Fundamental Rights in the European Union and the European Convention on Human Rights and its Supplementary Protocols (Dnr 2020-04206, Analys av jon- och biomolekylkoncentrationer i svett via sensorer applicerade på huden för att bestämma individens fysiologiska belastning). ${ }^{4,5}$ Furthermore, an informed consent was agreed with each subject before the on-body tests. This informed consent describes the aims, methods and implications of the research, the nature of the investigations and any benefits, risks or discomfort that may ensue during the test. 
Tables

Table S1. Compositions of the outer membranes used in lactate biosensors.

\begin{tabular}{cccccc}
\hline Mmbrane & Solvent & $\begin{array}{c}\text { PVC } \\
(\mathbf{m g ~ m L}\end{array}$ & $\begin{array}{c}\text { DOS } \\
\left(\mathbf{m g ~ m L}^{-1}\right)\end{array}$ & $\begin{array}{c}\text { TDMAC } \\
\left(\mathbf{m g ~ m} \mathbf{~ m}^{-1}\right)\end{array}$ & $\begin{array}{c}\text { ETH 500 } \\
\left(\mathbf{m g ~ m L}^{-1}\right)\end{array}$ \\
\hline M1 & THF & 33 & 66 & 0 & 0 \\
M2 & THF & 33 & 66 & 0.5 & 0 \\
M3 & THF & 33 & 66 & 0 & 3 \\
M4 & THF & 33 & 66 & 0 & 9 \\
\hline
\end{tabular}


Table S2. Lactate concentration obtained during on-body tests using the epidermal patch and IC measurements. The difference between both methods are also provided in the table. Notably, the values observed with the lactate biosensor were calculated as the average of lactate concentration coinciding with the sweat collection time.

\begin{tabular}{|c|c|c|c|c|c|c|}
\hline \multirow[t]{2}{*}{ TEST } & \multirow[t]{2}{*}{ Subject } & \multirow{2}{*}{$\begin{array}{l}\text { Average } \\
\text { power } \\
\text { (W) }\end{array}$} & \multirow{2}{*}{$\begin{array}{l}\text { Collection } \\
\text { time } \\
\text { (min) }\end{array}$} & \multirow[t]{2}{*}{ Zone } & \multicolumn{2}{|c|}{ Lactate $(\mathrm{mM})$} \\
\hline & & & & & Sensor & IC \\
\hline On-T1 & 1 & 110 & $0-15$ & Back & 12.0 & 13.7 \\
\hline On-T1 & 1 & 147 & $15-30$ & Back & 10.4 & 12.2 \\
\hline On-T1 & 1 & 208 & $30-45$ & Back & 8.8 & 15.0 \\
\hline On-T1 & 1 & 102 & $45-60$ & Back & 8.0 & 13.9 \\
\hline On-T2 & 2 & 130 & $0-15$ & Back & 18.0 & N/A \\
\hline On-T2 & 2 & 160 & $15-30$ & Back & 14.3 & 15.1 \\
\hline On-T2 & 2 & 90 & $30-45$ & Back & 14.7 & 11.6 \\
\hline On-T2 & 2 & 75 & $45-60$ & Back & 12.4 & 8.1 \\
\hline On-T3 & 2 & 90 & $0-15$ & Back & 6.0 & N/A \\
\hline On-T3 & 2 & 100 & $15-30$ & Back & 20.1 & 17.5 \\
\hline On-T3 & 2 & 120 & $30-45$ & Back & 14.1 & 11.9 \\
\hline On-T3 & 2 & 140 & $45-60$ & Back & 14.4 & 11.0 \\
\hline On-T4 & 3 & 100 & $0-15$ & Forehead & 19.0 & 20.1 \\
\hline On-T4 & 3 & 100 & $15-30$ & Forehead & 13.2 & 16.6 \\
\hline On-T4 & 3 & 220 & $30-45$ & Forehead & 22.9 & 15.6 \\
\hline On-T4 & 3 & 70 & $45-60$ & Forehead & 18.2 & 12.6 \\
\hline On-T5 & 3 & 145 & $30-60$ & Thigh & 15.7 & 22.7 \\
\hline On-T5 & 3 & 122 & $0-60$ & Thigh & 15.3 & 24.7 \\
\hline On-T6 & 4 & - & 30 & Arm & 15.1 & 17.1 \\
\hline On-T7 & 5 & - & 15 & Arm & 13.4 & 17.4 \\
\hline
\end{tabular}




\section{Figures}

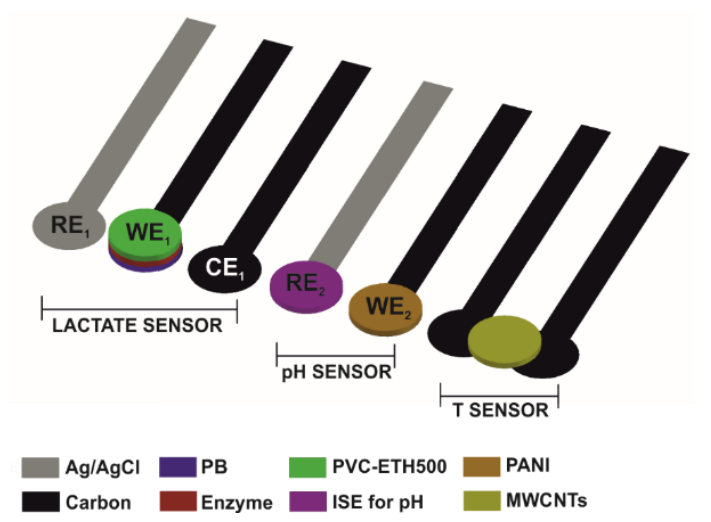

Figure S1. Schematic draw of $\mathrm{pH}, \mathrm{T}$, and lactate sensors layer.

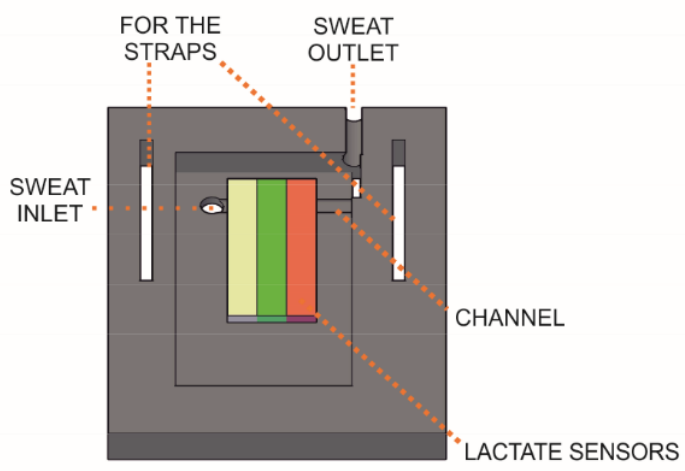

Figure S2. Schematic draw of one channel cell. 

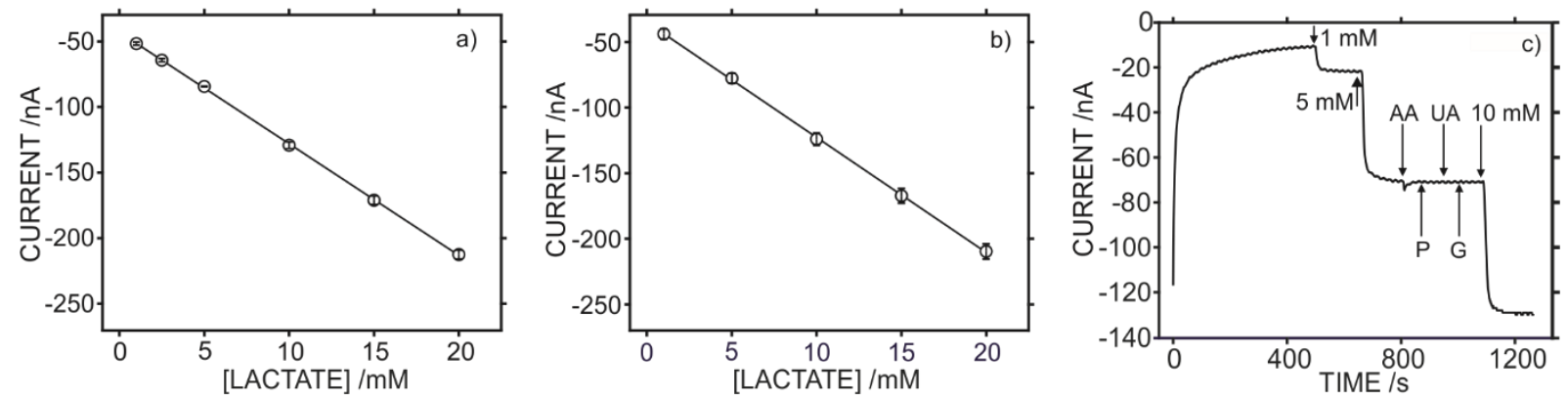

Figure S3. Characterization of the lactate biosensor in batch mode (stirred conditions, $300 \mathrm{rpm}$ ) in artificial sweat, with an applied potential of $-0.05 \mathrm{~V}$ and using the screen-printed $\mathrm{Ag} / \mathrm{AgCl}$ as the reference electrode. Average calibration graph with error bars corresponding to (a) three successive calibrations, and (b) three twin lactate sensors. (c) Response of lactate sensor to several interferences. The order of additions are: $1 \mathrm{mM}$ lactate, $5 \mathrm{mM}$ lactate, $0.1 \mathrm{mM}$ ascorbic acid (AA), $0.1 \mathrm{mM}$ uric acid (UA), $0.1 \mathrm{mM}$ pyruvate $(\mathrm{P}), 0.25 \mathrm{mM}$ glucose $(\mathrm{G})$, and $5 \mathrm{mM}$ lactate.

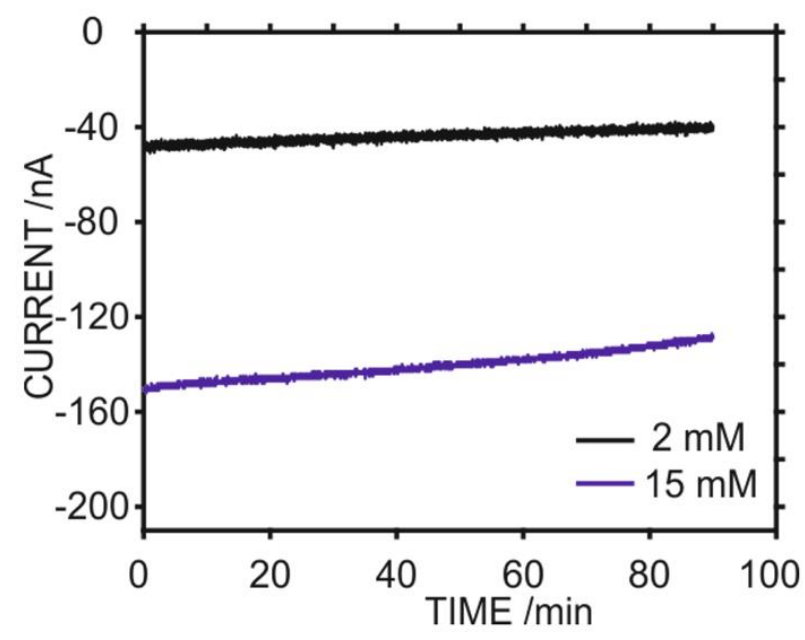

Figure S4. Time trace of the chronoamperometric response $(<1 \mathrm{~h})$ of the lactate biosensor in artificial sweat containing $2 \mathrm{mM}$ (black) and $15 \mathrm{mM}$ (purple) of lactate. 


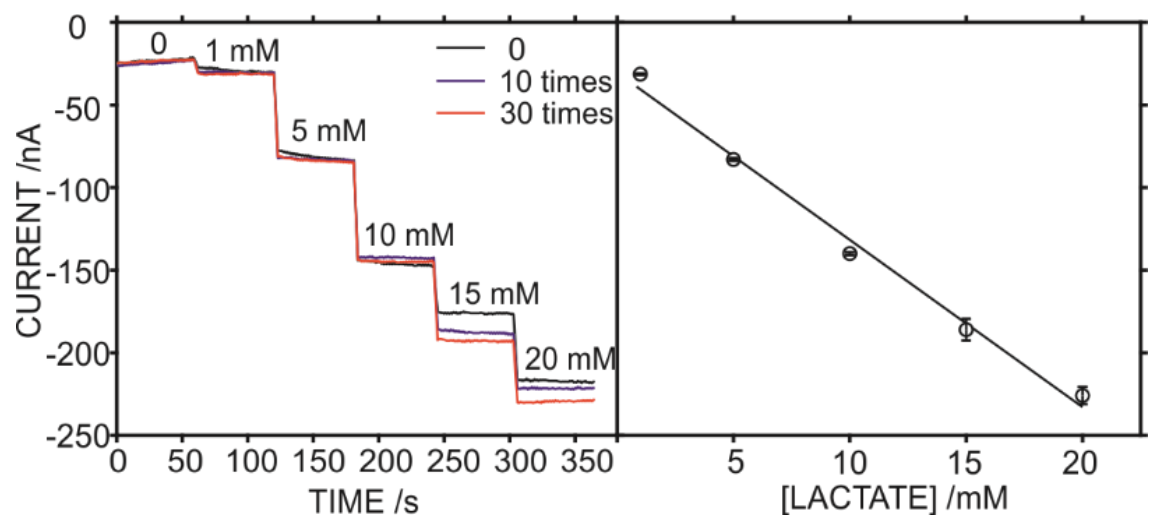

Figure S5. Resiliency test consisting of the application of an increasing number of torsion strain. Left: Dynamic responses for increasing concentrations of lactate. Right: corresponding calibration curves.
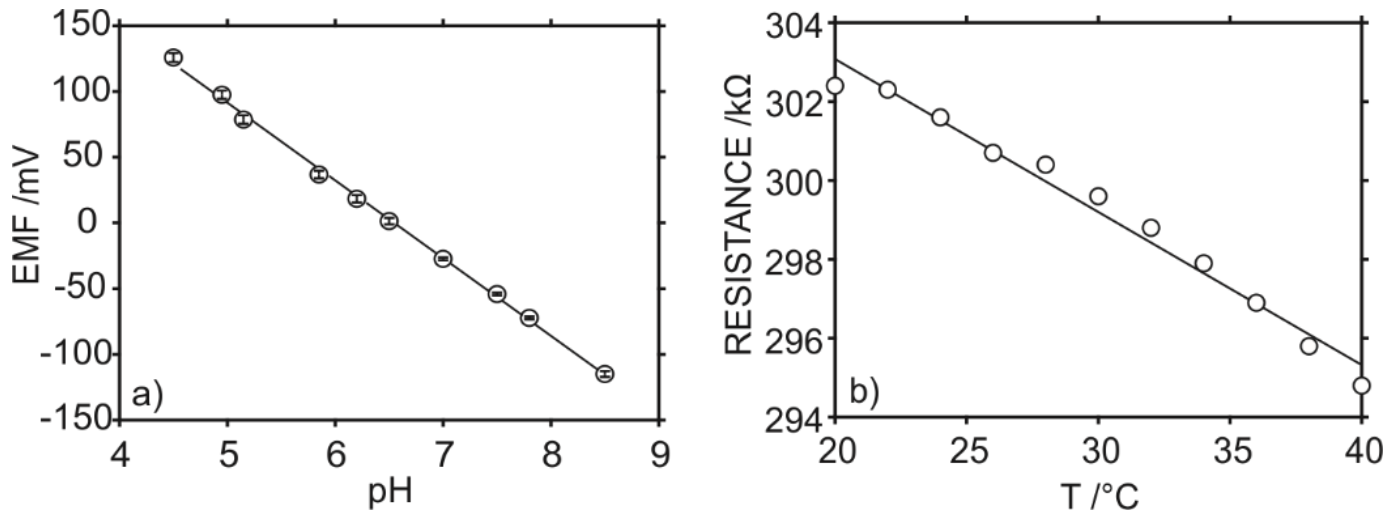

Figure S6. Calibration curve for the $\mathrm{pH}$ and T sensors.
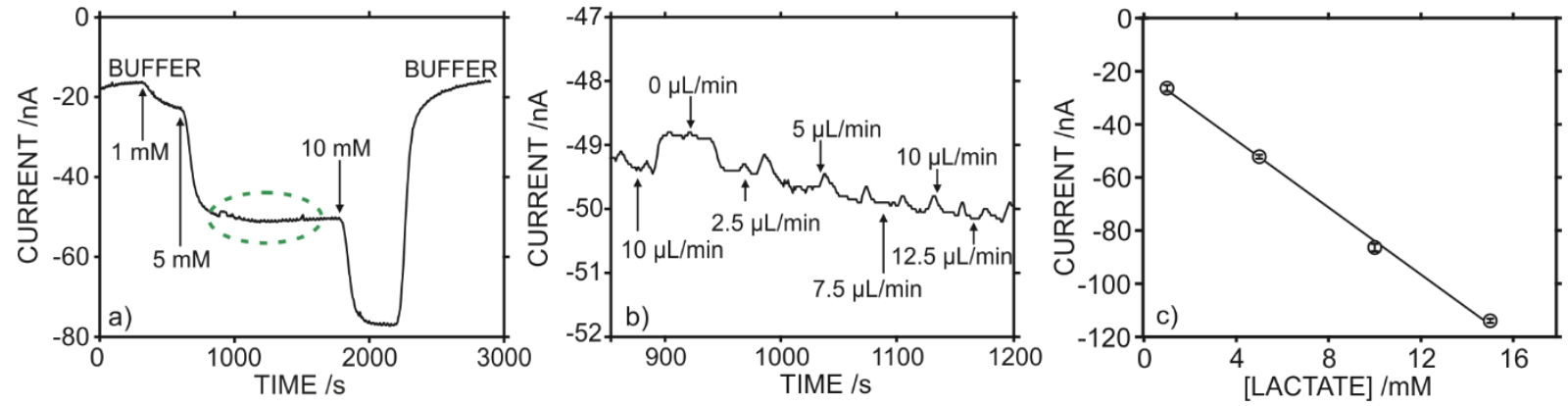

Figure S7. (a) Influence of the flow rate on the chronoamperometric response of the lactate biosensor tested in flow mode. (b) Zoom-in from the previous figure. (c) Average calibration curve with error bars for reversibility stud-ies. 

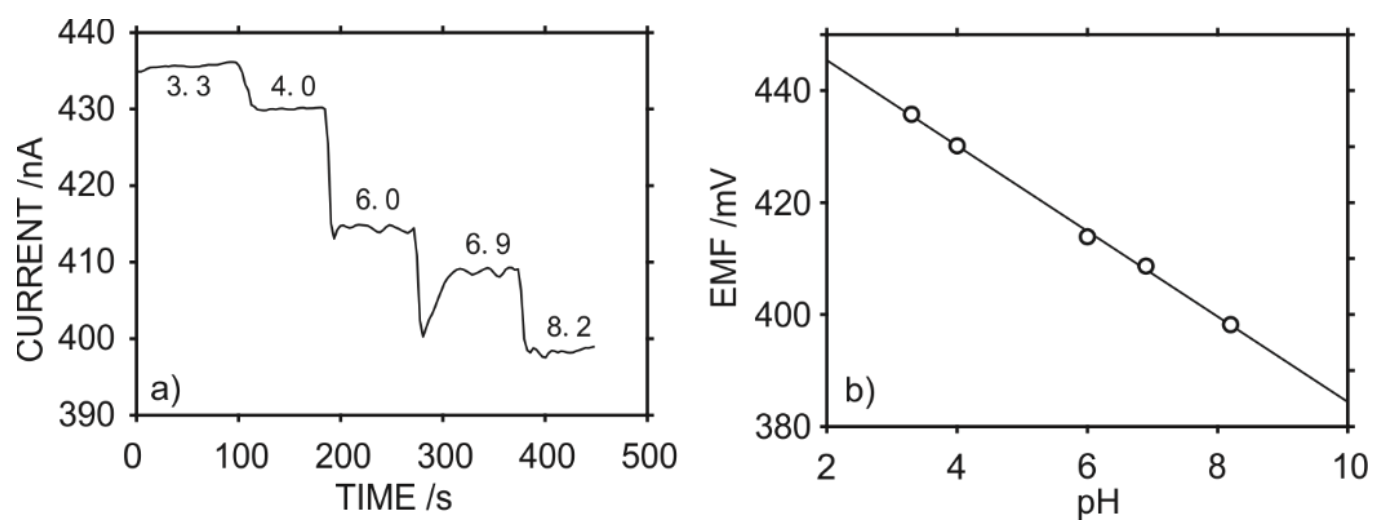

Figure S8. (a) Potentiometric response of an electrode composed of Carbon/CNTs/ETH500 membrane at different $\mathrm{pH}$ values. (b) Corresponding calibration graph.

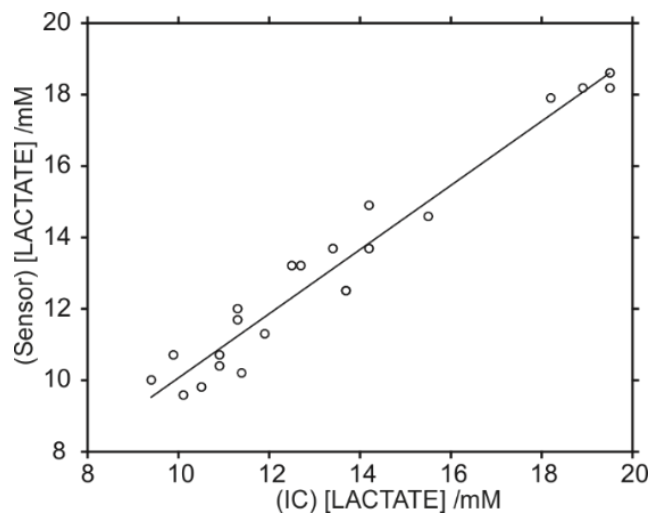

Figure S9. Correlation plot between lactate measurements in sweat performed off-body with the biosensor and with ion chromatography. 


\section{References}

1. Wiorek, A.; Parrilla, M.; Cuartero, M.; Crespo, G. n. A., Epidermal Patch with Glucose Biosensor: $\mathrm{pH}$ and Temperature Correction toward More Accurate Sweat Analysis during Sport Practice. Analytical Chemistry 2020, 92 (14), 10153-10161.

2. Wiorek, A.; Cuartero, M.; De Marco, R.; Crespo, G. A., Polyaniline Films as Electrochemical-Proton Pump for Acidification of Thin Layer Samples. Analytical Chemistry 2019, 91 (23), 14951-14959.

3. Parrilla, M.; Ortiz-Gomez, I.; Canovas, R.; Salinas-Castillo, A.; Cuartero, M.; Crespo, G. A., Wearable potentiometric ion patch for on-body electrolyte monitoring in sweat: toward a validation strategy to ensure physiological relevance. Analytical chemistry 2019, 91 (13), 8644-8651.

4. Convention, E., Charter of Fundamental Rights of the European Union. 2000.

5. Convention, E., European Convention on Human Rights. 1953. 